Article DOI:

https://doi.org/10.35293/srsa.v42i2.81

\title{
Xulu-Gama, Nomkhosi, Hostels in South Africa: Spaces of Perplexity, Pietermaritzburg: University of KwaZulu- Natal Press, 2017, 251 pp.
}

The housing of Black workers has a specific history in South Africa, and the issue has been researched across a variety of disciplines from Anthropology through Public Health and Sociology. Nomkhosi Xulu-Gama in Hostels in South Africa: Spaces of Perplexity, tackles how the apartheid era migrant workers' hostels have been transformed into post-apartheid South Africa's Community Residential Units (CRUs).

The book is divided into three parts. Part 1 is made up of Chapter 1 and 2 and is titled Hostels. In Chapter 1 the author looks at the historical overview of the KwaMashu hostel as a product of the migrant labour system of 1886. Chapter 2 goes on to explore how the nature of hostels changed in 1994 with the creation of new structures in the form of CRUs, drifting from men only accommodation to family households.

Part 2 incorporates Chapter 3, 4 and 5 and is titled livelihoods. Chapter 3 details the everyday struggles and opportunities of both women and men of different ages and background at the KwaMashu Hostel. Chapter 4 specifically investigates the declining or 'shrinking' opportunities as Nomkhosi defines it. With the increasing unemployment rate (which is part of the triple challenges in South Africa including inequality and poverty), hostel dwellers are not necessarily migrant workers anymore as others look into other ways of making income and living. Chapter 5 discusses the means of making an income by hostel dwellers and these are sexuality, criminality and social grants. While social grants are provided for by the government and could be regarded as another form of income, sexuality and criminality are other means used by both men and women who live in the historical KwaMashu Hostel to make a living. Xulu-Gama notes that given the escalating participation of women in the labour market, the majority of the women in the labour market are subject to the second segment of the market. This has been instrumental to the changes in household heads, structures, relation and size (p 8). 
Part 3 consists of the three chapters and it is titled 'producing perplexity' In Chapter 6, Xulu-Gama looks at the emerging cultural formations in hostels. This includes both formal and informal associations, fragmentation, disintegration, separation and disassociations that hostel dwellers have formed, unformed and deformed across the rural-urban spectrum ( $p$ 183). Chapter 7 examines the production of gendered spaces at KwaMashu Hostel. Given that historically it was a single-sex residence and today houses even women and children, the author explores the changes as well as the roles and responsibilities of men and women (p 199). Xulu-Gama looks at the relations between men and women, the relations among women as well as relations among men. She further discusses the gender roles and responsibilities in hostels today and how gendered spaces are produced, reproduced and redefined continuously in both rural and urban areas ( $\mathrm{p}$ 217). Chapter 8 explores the household and housing dynamics from household headship and gender relations; the author argues that hostels today continue to be highly gendered spaces and the dynamics of household and house structures continues. The author asserts that hostels challenge patriarchal dominance and asserts that although they remain to be highly gendered spaces, hostels resume to ravel household and housing structures.

In the final instance, Xulu-Gama dedicates 7 pages concluding the KwaMashu Hostel as 'spaces of perplexity' by discussing rural-urban migration as well as challenges and opportunities for hostel dwellers today. As far as her arguments are concerned, Xulu-Gama skilfully shows how men and women navigate gender, love, violence, the state and economic insecurity, as Mark Hunter puts it right on the book cover.

The essence of this book touches on the subtitle of the book: 'Spaces of Perplexity' Xulu-Gama argues that issues of migration, labour employment, gender, sex, socially and geographically extended families (rural-urban links), housing and politics have drastically changed over the last years at the KwaMashu hostel ( p 2).

This book is a significant contribution to conversations on hostel literature in South Africa. It is based on sound research on the current state of KwaMashu Hostel and as Xulu-Gama states "people in hostels today are producing livinghoods, reworking their lives and making their histories in conditions, not of their own making” ( $p$ 95). Based on the foregoing observation, this book is recommended for scholars, policymakers and other parties interested in the 
evolving discourses about housing and sanitation studies.

\section{Lebogang Tiego Legodi}

Auwal Socio-Economic Research Institute \& University of Limpopo, South Africa 
